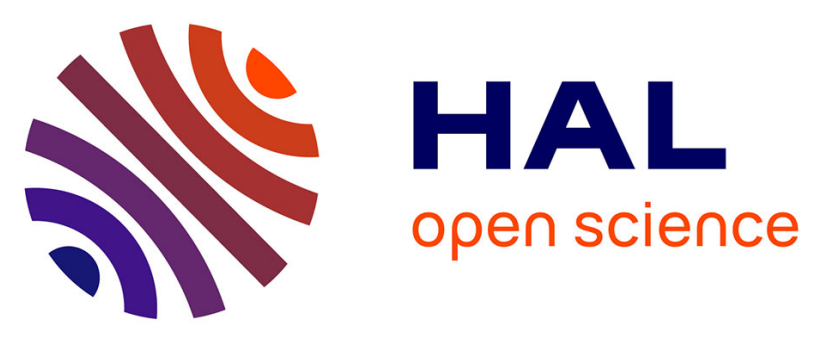

\title{
Renal Infarction and Its Consequences for Renal Function in Patients With Cardiac Amyloidosis
}

\author{
Julien Dang, Mukedaisi Abulizi, Anissa Moktefi, Khalil El Karoui, \\ Jean-François Deux, Diane Bodez, Fabien Le Bras, Karim Belhadj, Philippe \\ Remy, Pauline Issaurat, et al.
}

\section{To cite this version:}

Julien Dang, Mukedaisi Abulizi, Anissa Moktefi, Khalil El Karoui, Jean-François Deux, et al.. Renal Infarction and Its Consequences for Renal Function in Patients With Cardiac Amyloidosis. Mayo Clinic Proceedings, 2019, 94, pp.961 - 975. 10.1016/j.mayocp.2019.02.012 . hal-03485053

\section{HAL Id: hal-03485053 https://hal.science/hal-03485053}

Submitted on 20 Dec 2021

HAL is a multi-disciplinary open access archive for the deposit and dissemination of scientific research documents, whether they are published or not. The documents may come from teaching and research institutions in France or abroad, or from public or private research centers.
L'archive ouverte pluridisciplinaire HAL, est destinée au dépôt et à la diffusion de documents scientifiques de niveau recherche, publiés ou non, émanant des établissements d'enseignement et de recherche français ou étrangers, des laboratoires publics ou privés.

\section{(ㄷ)(1) $\$$}

Distributed under a Creative Commons Attribution - NonCommerciall 4.0 International 


\section{Renal infarction and its consequences for renal function in patients with cardiac amyloidosis}

Julien Dang, MD*1,2,3,12; Mukedaisi Abulizi, MD*4,12; Anissa Moktefi, MD ${ }^{2,3,5,12}$, Khalil El Karoui, $\mathrm{MD}, \mathrm{PhD}^{1,2,3,12}$; Jean-François Deux, $\mathrm{MD}, \mathrm{PhD}^{6,12}$; Diane Bodez $\mathrm{MD}, \mathrm{PhD}^{7,12}$; Fabien Le Bras, $\mathrm{MD}^{8,12}$; Karim Belhadj, $\mathrm{MD}^{8,12}$; Philippe Remy, $\mathrm{MD}^{1,2,3,12}$, Pauline Issaurat $\mathrm{MD}^{7,12}$;Violaine Plante-Bordeneuve, MD, PHD ${ }^{9,12}$, Valérie Molinier-Frenkel, $\mathrm{MD}, \mathrm{PhD}^{10,12}$, Pascale Fanen, $\mathrm{MD}, \mathrm{PhD}^{11,12}$, Soulef Guendouz, $\mathrm{MD}^{7,12}$; Mounira Kharoubi, $\mathrm{PhD}^{7,12}$; Emmanuel Itti, $\mathrm{MD}, \mathrm{PhD}^{4,12}$; Thibaud Damy, $\mathrm{MD}, \mathrm{PhD}^{\circ 7,12}$; Vincent Audard, $\mathrm{MD}, \mathrm{PhD}^{\circ 1,2,312}$.

1. Assistance Publique des Hôpitaux de Paris (AP-HP), Groupe Hospitalier Henri-Mondor/ Albert Chenevier, Service de Néphrologie et Transplantation, Créteil, 94000, France.

2. Equipe 21, Institut National de la Santé et de la Recherche Médicale (INSERM) U955, Institut Mondor de Recherche Biomédicale (IMRB), Créteil, 94000, France.

3. AP-HP, Groupe Hospitalier Henri-Mondor/ Albert Chenevier, Centre de Référence Maladie Rare Syndrome Néphrotique Idiopathique de l'Enfant et de l'Adulte, Créteil, 94000, France.

4. AP-HP, Groupe Hospitalier Henri-Mondor/Albert Chenevier, Service de Médecine Nucléaire, Créteil, 94000, France.

5. AP-HP, Groupe Hospitalier Henri-Mondor/Albert Chenevier, Service de Pathologie, Créteil, France.

6. AP-HP, Groupe Hospitalier Henri-Mondor/Albert Chenevier, Service d'Imagerie Médicale, Créteil, 94000, France.

7. AP-HP, Groupe Hospitalier Henri-Mondor/Albert Chenevier, Service de Cardiologie, Créteil, 94000, France.

8. AP-HP, Groupe Hospitalier Henri-Mondor/Albert Chenevier, Unité Hémopathies Lymphoïdes, Créteil, 94000, France.

9. AP-HP, Groupe Hospitalier Henri-Mondor/Albert Chenevier, Service de Neurologie, Créteil, 94000, France.

10. AP-HP, Groupe Hospitalier Henri-Mondor/Albert Chenevier, Département d'Hématologie-Immunologie biologique, Créteil, 94000, France.

11. AP-HP, Groupe Hospitalier Henri-Mondor/ Albert Chenevier Département de Biochimie, Biologie moléculaire, Pharmacologie et Génétique médicale, Créteil, 94000, France.

12. Réseau Amylose Mondor, Groupe de Recherche Clinique sur les Amyloses, Centre de référence des amyloses cardiaques, AP-HP, Groupe Hospitalier Henri-Mondor/Albert 
Chenevier, Université Paris Est, Faculté de médecine, INSERM (Institut National de la Santé et de la Recherche Médicale) U955 Créteil, 94000, France

* JD and MA contributed equally to this work

${ }^{\circ} \mathrm{TD}$ and VA contributed equally to this work

\section{Reprints and correspondance:}

Dr Vincent Audard, Service de Néphrologie et Transplantation, Groupe Hospitalier Henri Mondor-Albert Chenevier, 51, ave du Marechal-de-Lattre-de-Tassigny, 94010 Créteil Cedex, France. Tel: +33(0)149814446; Fax: +33(0)149814452; e-mail: vincent.audard@aphp.fr.

and

Dr Thibaud Damy, centre de référence des amyloses cardiaques et service de cardiologie, Groupe Hospitalier Henri Mondor-Albert Chenevier, 51, ave du Marechal-de-Lattre-deTassigny, 94010 Créteil Cedex, France. Tel: +33(0)149812253, Fax: +33(0)149814224; email: thibaud.damy@aphp.fr

Financial support and conflict of interest disclosure: The authors have no conflict of interest to declare and did not receive financial support 


\section{ABSTRACT}

Objective: To describe in patients with cardiac amyloidosis, the prevalence and risk factors of renal infarction (RI)

Patients and Methods: Eighty-seven patients who underwent renal ${ }^{99 \mathrm{~m}} \mathrm{Tc}-$ labeled DMSA scintigraphy in the Amyloidosis Referral Center of Henri-Mondor Hospital, from 1 October 2015 through 28 February 2018, were evaluated

Results: Three groups of patients were identified according to the underlying amyloidosis disorder: AL amyloidosis in 24 patients, mutated-transthyretin (TTR) (ATTRm) amyloidosis in 24 patients and wild-type TTR (ATTRwt) amyloidosis in 39 patients. Patients with ATTRwt amyloidosis were older $(P<.001)$, more likely to be men $(P=.02)$, to have arrhythmic heart diseases $(P<.001)$, and to be on anticoagulation treatment $(P<.001)$. Patients with AL amyloidosis had significantly higher NT-proBNP levels $(P=.02)$ and were more likely to have nephrotic syndrome $(P<.001)$. RI was detected in 18 patients $(20.7 \%)$, at similar frequencies in the various groups. Baseline urinary protein/creatinine ratio was the only parameter for which a significant difference $(P=.03)$ was found between patients with and without RI diagnoses. The likelihood of RI diagnosis was $47.1 \%$ in the presence of AKI and $14.5 \%$ in its absence $(P=.003)$. Overall heart transplant-censored patient survival did not differ significantly between patients with and without RI $(P=.64)$ but death-and heart transplantcensored renal survival was significantly lower in patients with $\mathrm{RI}(P<.001)$.

Conclusions: Our study suggests that prevalence of RI in patients with cardiac amyloidosis is higher than previously thought, regardless of the underlying amyloidosis disorder. AKI in a patient with cardiac amyloidosis should alert clinicians to the possibility of RI 
Abbreviations and Acronyms:

RI (Renal infarction), DMSA (Dimercaptosuccinic acid), ATTRwt (Wild-type TTR amyloidosis), ATTRm (Mutated-TTR amyloidosis), AKI (Acute kidney injury), CKD (Chronic kidney disease), eGFR (Estimated glomerular filtration rate), KDIGO (Kidney Disease Improving Global Outcomes) 


\section{INTRODUCTION}

Amyloidoses are a heterogeneous group of diseases classified according to the nature of the main precursor protein forming the amyloid fibrils. ${ }^{1,2}$ The most prevalent types of amyloidosis are acquired systemic immunoglobulin light chain amyloidosis (AL amyloidosis), AA amyloidosis, hereditary forms due to genetic variants encoding abnormal proteins and wild-type transthyretin (TTR) amyloidosis. ${ }^{1,3}$ Hereditary TTR amyloidosis, caused by various mutations of the TTR gene, is one of the most frequent causes of hereditary amyloidosis. In some patients, amyloidosis with prominent cardiac involvement may be associated with an aging process known as senile systemic amyloidosis, related to nonmutated or wild-type TTR amyloidosis (ATTRwt). ${ }^{4}$ In patients with systemic amyloidosis, cardiac involvement (the most relevant prognosis factor) and kidney impairment are two of the most frequent clinical manifestations ${ }^{5,6,7}$ Regardless of the underlying amyloid precursor protein, the natural course of renal disease involves a progressive decline of renal function, leading to end- stage renal disease. ${ }^{89}$ Patients with amyloidosis frequently have ventricular or supraventricular arrhythmias and/or nephrotic syndrome, both of which are known to be associated with a significant risk of arterial thromboembolic events, such as renal infarction (RI). ${ }^{10,11}$ Nevertheless, the prevalence of RI, the risk factors for this condition and the outcome of patients presenting RI in a context of cardiac amyloidosis have never been investigated in detail. We previously showed, in a retrospective French multicenter study, that amyloidosis was a rare finding in the context of RI. ${ }^{12}$ Some arterial thromboembolic events have been reported in patients with AL amyloidosis in the absence of both arrhythmia and intracardiac thrombi. ${ }^{13}$ Most amyloidosis patients have non-optimal renal function or have been fitted with heart devices. The indications for computed tomography (CT) scans and magnetic resonance imaging (MRI) must therefore be considered carefully. In this study, after

validation of this examination in one patient with biopsy-proven RI, we used renal ${ }^{99 \mathrm{~m}} \mathrm{Tc}$ - 
labeled dimercaptosuccinic acid (DMSA) scintigraphy to assess the prevalence, risk factors, clinical presentation and consequences of RI in a large cohort of patients with a diagnosis of cardiac amyloidosis. 


\section{PATIENTS AND METHODS}

\section{Study population and cardiac evaluation}

This observational study was conducted in the Reference Center for Amyloidosis at Henri Mondor Hospital. We included 104 adult patients referred to our center for suspected cardiac

amyloidosis (Figure 1). Based on the availability of facilities for performing ${ }^{99 \mathrm{~m}} \mathrm{Tc}$-labeled DMSA renal scintigraphy at our center, two patients underwent such exploration each Friday. Patients were randomly included in the protocol as a function of their presence at the referral center on a Friday, regardless of their clinical and biological characteristics. Baseline demographic, clinical, biological and echocardiographic characteristics were collected from the previous three months of routine follow up before renal scintigraphy. These data were analyzed exclusively for patients with a definitive diagnosis of confirmed cardiac amyloidosis. Echocardiography was performed with a Vivid 7 system (Vivid 7; GE Healthcare, Horton, Norway), in accordance with the international guidelines. ${ }^{14}$ Data were stored digitally at the cardiac amyloidosis center and were analyzed offline with Echo-PAC software (V7.0.0, GE Vingmed Ultrasound) (Supplemental Material). Cardiac biomarkers, including amino-terminal pro-brain natriuretic peptide (NT-proBNP) and cardiac troponins (cTn), were determined at baseline.

Diagnosis of cardiac amyloidosis according to the underlying disorder causing amyloid production

The diagnosis of cardiac amyloidosis was confirmed on the basis of heart involvement, defined as an interventricular septum thickness (IVST) $\geq 12 \mathrm{~mm}$, associated with Congo redpositive deposits and apple-green birefringence under polarized light on accessory salivary 
glands, heart and/or kidney biopsy specimens and/or a TTR mutation detected by gene sequencing. Tissues with Congo red-positive deposits were not analyzed by mass spectrometry, but all formalin-fixed paraffin-embedded tissues were systematically stained with polyclonal antibodies against TTR (Dako, Glostrup, Denmark), monoclonal antibodies against serum amyloid A protein (Dako, Glostrup, Denmark) and immunoglobulin light chains (Clinisciences, BD Biotech, Popradzka, Slovakia). A second frozen biopsy specimen was systematically subjected to immunofluorescence analyses with polyclonal fluorescein isothiocyanate-conjugated (FITC) antibodies against the human $\kappa$ and $\lambda$ light chains (Dako, Glostrup, Denmark). AL amyloidosis was diagnosed on the basis of the biological detection of a monoclonal gammopathy, with an endomyocardial or extracardiac biopsy specimen (accessory salivary glands or kidney) displaying specific labeling with anti- $\kappa$ or anti- $\lambda$ lightchain antibodies. The type of monoclonal light chain and the initial serum free light chain concentration were recorded for all patients. The diagnosis of mutated-TTR (ATTRm) amyloidosis required the identification of a mutation in the gene encoding TTR together with strong cardiac fixation on ${ }^{99} \mathrm{TC}$-bisphosphonate bone scintigraphy and/or Congo red staining and anti-TTR antibody labeling on extracardiac or endomyocardial biopsy. The TTR variant was determined for all patients. ATTRwt amyloidosis was defined as for ATTRm, except that patients had no mutation of the TTR gene on sequencing.

\section{Renal ${ }^{99 m}$ Tc-labeled DMSA scintigraphy}

Renal scintigraphy was performed regardless of renal function at baseline or on the day of the scintigraphy (in patients with acute kidney injury (AKI) or chronic kidney disease (CKD) and in those with normal estimated glomerular filtration rate (eGFR) for the detection of possible subclinical RI). Patients with a history of renal pyelonephritis, which is considered a 
differential diagnosis for cortical defects, were therefore not included in this study. Renal scintigraphy was performed with a hybrid SPECT/CT PRECEDENCE16 camera (Philips, Da Best, The Netherlands) equipped with large field-of-view, low-energy, high-resolution parallel collimators. It involved planar acquisition of the upper abdomen in the anterior and posterior views, 4 to 6 hours after the injection of $110-130 \mathrm{MBq}{ }^{99 m} \mathrm{Tc}-\mathrm{DMSA}$, followed by tomoscintigraphy centered on the kidneys and coupled with low-dose computed tomography (CT). Images were interpreted on the basis of a consensus between two senior physicians (MA, EI) blind to the patient's characteristics. RI was defined as a triangularshaped, peripheral cortical defect. Images were scored semi-quantitatively by the assignment of one of three grades: grade 0 for no cortical defect or a defect attributable to a cyst identified on CT, grade I for moderate cortical defects in which some background parenchyma was visible within the defect (partial defect); grade II for severe cortical defects with no remaining background parenchyma visible within the defect (cortical amputation). Renal infarcts were classified as focal if a single wedge-shaped lesion was observed or multifocal (two or more lesions). Before initiating the enrollment of patients with suspected cardiac amyloidosis, we validated ${ }^{99 \mathrm{~m}} \mathrm{Tc}$-labeled DMSA scintigraphy as a technique as effective and relevant for RI diagnosis as MRI, by comparing these two examinations in a patient with RI proven by renal graft biopsy.

\section{Renal function evaluation and follow-up}

AKI was defined according to Kidney Disease Improving Global Outcomes (KDIGO) criteria. ${ }^{15}$ CKD based on eGFR calculated with the three-variable modification of diet in renal disease (MDRD) formula was defined according KDIGO criteria. ${ }^{16}$ Other renal function parameters included the evaluation of urinary protein/creatinine ratio (PCR) expressed as 
$\mathrm{mg} / \mathrm{mmol}$ of creatinine. Past medical history and baseline therapeutic management were noted for all patients. Some clinical (blood pressure, abdominal pain and fever) and biological (level of lactate dehydrogenase, C-reactive protein and neutrophil count) data classically associated with RI were recorded at the time of renal scintigraphy. Follow-up began when the renal scintigraphy was performed. Where possible, we compared the following between the groups of patients with and without RI: percentage increase in creatinine levels between renal scintigraphy and last follow-up evaluation. All patient deaths occurring during the follow-up period were recorded.

\section{Statistical analysis and ethical considerations}

Continuous variables are expressed as mean \pm standard deviation (SD) or median (interquartile range), depending on the distribution. Dichotomous data are expressed as percentages. For qualitative variables, frequency differences were compared in $\chi^{2}$ tests with Pearson's correction. For continuous data, Mann-Whitney tests were used to compare pairs of groups, and Kruskal-Wallis tests were used to compare three groups at a time. Statistical analysis was performed with SPSS software (version 19.0 for Windows 2010 SPSS Inc.). $P$-values <.05 were considered statistically significant. We assessed the prognostic effect of RI on patient survival, by comparing patients with and without RI. Log-rank tests and Kaplan-Meier curves (Stat 14 statistical software) were used to compare time-to-event variables between the two groups. Patient survival was censored for heart transplantation. We also investigated kidney survival censored for death and heart transplantation, using a combined endpoint consisting of a $50 \%$ increase in serum creatinine concentration between baseline and last follow-up or the need for renal replacement therapy (dialysis or kidney transplantation). This study was performed in accordance with the Declaration of Helsinki. All patients provided written 
informed consent before study enrolment. The study protocol was approved by our local ethics committee (Créteil) and by the French Comité National de l'Informatique et des Libertés (CNIL number 1431858). Data collection was approved by DIRC Ile de France (DC 2009-930). 


\section{RESULTS}

Validation of ${ }^{99 m}$ Tc-labeled DMSA renal scintigraphy for the detection of potential renal infarction

We first validated the use of ${ }^{99 m}$ Tc-labeled DMSA renal scintigraphy for screening patients for RI. A 56-year-old man who underwent kidney transplantation for diabetic nephropathy was admitted to our hospital for acute graft failure. Renal graft biopsy specimens revealed unexpected and severe recent renal cortical necrosis (Figure 2A, 2B). ${ }^{99 \mathrm{~m}} \mathrm{Tc}$-labeled DMSA scintigraphy demonstrated three cortical defects suggestive of RI in the graft, with this diagnosis subsequently confirmed by magnetic resonance imaging (MRI) (Figure 2C, 2D). Based on this promising preliminary finding showing a close correlation between renal biopsy, renal scintigraphy and MRI findings, we performed renal ${ }^{99 \mathrm{~m}} \mathrm{Tc}$-labeled DMSA scintigraphy some patients referred to our amyloidosis center for suspected cardiac amyloidosis between 1 October 2015 and 28 February 2018. Thus, during the study period, 676 patients were admitted to our institution for screening for suspected cardiac amyloidosis. The diagnosis of cardiac amyloidosis diagnosis was confirmed in 431 cases (AL in 131 cases, ATTRm in 100 cases, ATTRwt in 174 cases and another form in 26 cases), but 343 of these patients did not undergo renal scintigraphy (Figure 1). We found that baseline eGFR did not differ significantly between the 318 cardiac amyloidosis patients (including exclusively patients with AL (n=107), ATTRm $(n=76)$ and ATTRwt $(n=135))$ who did not undergo renal scintigraphy and cohort of 87 patients (with similar types of amyloidosis, AL ( $n=24)$, ATTRm $(n=24)$ and ATTRwt $(n=39))$ who did $\left(\right.$ eGFR $=60(47-78)$ versus $55(41-72) \mathrm{mL} / \mathrm{mn} / 1.73 \mathrm{~m}^{2}$, $P=.06)$ 
Baseline demographic, clinical, biological and echocardiographic data by patient subgroup

Amyloidosis with cardiac involvement was confirmed in 88 of the 104 patients who underwent renal scintigraphy (Figure 1). One patient with a diagnosis of mutated ApoA2 systemic amyloidosis and bilateral RI was excluded from the analysis. Extensive investigations led us to conclude that 16 of these 104 patients did not have cardiac amyloidosis. Endomyocardial biopsy was performed in one case, and none of the patients had amyloid deposits on accessory salivary gland biopsy specimens. The diagnosis of heart involvement not due to amyloidosis was also based on the absence of immunoglobulin components or changes in free light chain concentration, negative test results based on the sequencing of all the genes known to be associated with amyloidosis and a lack of fulfillment of multimodal screening criteria for amyloidosis (echocardiography, bone scintigraphy, cardiac MRI). ${ }^{99} \mathrm{TC}$-bisphosphonate bone scintigraphy was performed in all 16 patients and was negative in all cases. The main differences between patients with cardiac involvement related or unrelated to amyloidosis are summarized in the Supplemental Table. We found that the patients with cardiac amyloidosis were older $(P=.009)$, had more severe cardiac disease based on global strain $(P<.001)$ and were more likely to be taking anticoagulants $(P=.02)$ than the patients without amyloidosis. In addition, troponin and NT-proBNP levels were higher $(P<.001$ and $P<.001$, respectively), and albumin levels were lower in cardiac amyloidosis patients $(P=.003)$. Patients were assigned to three groups on the basis of the underlying amyloidosis disorder: AL amyloidosis in 24 cases (27.5\%), ATTRm in 24 patients (27.5\%) and ATTRwt in 39 patients (45\%). The baseline characteristics of the patients are summarized in Table1. The patients of the ATTRwt group were significantly older $(P<.001)$, and were more frequently men $(P=.02)$, to display paroxysmal or permanent auricular fibrillation $(P<.001)$ and to be on anticoagulation treatment $(P<.001)$ than the patients of the other subgroups. Patients with AL amyloidosis had significantly higher median levels of NT- 
pro BNP $(P=.02)$, median urinary PCR $(P<.001)$, lower blood albumin levels $(P=.001)$ and were more likely to have nephrotic syndrome at baseline $(P<.001)$. Other demographic, clinical and biological data and echocardiographic parameters did not differ significantly between the three groups of patients at baseline. The methods used for the definitive diagnosis of the different types of amyloidosis and the characteristics of these forms are shown in Table 1. Endomyocardial biopsy was performed in 28 cases in all, but was less frequent in the ATTRwt group than in the other groups $(P=.03)$, whereas renal biopsy was performed exclusively in patients from the AL amyloidosis group $(P=.001)$. The TTR variants found in the 24 patients of the ATTRm group are listed in the legend to Table 1.

Characteristics of patients with renal infarction demonstrated by ${ }^{99 m}$ Tc-labeled DMSA renal scintigraphy

${ }^{99}$ Tc-labeled DMSA renal scintigraphy revealed features consistent with RI diagnosis in 18 patients with cardiac amyloidosis $(20.7 \%)$ and in four of 16 patients $(25 \%)$ without cardiac amyloidosis $(P=.76)$ (Figure 1). Figure 3 illustrates the main findings of ${ }^{99 \mathrm{~m}} \mathrm{Tc}-\mathrm{DMSA}$ imaging for a patient with cardiac amyloidosis and RI. Thirteen patients $(72.2 \%)$ had a single defect of the renal parenchyma, whereas five patients (27.8\%) presented two or more lesions. Four patients $(22.2 \%)$ were classified as having grade I and $14(77.8 \%)$ as having grade II RI. The right kidney was involved in six patients $(33.4 \%)$, the left kidney in eight patients (44.4\%), and four patients $(22.2 \%)$ had bilateral RI. We then compared the baseline characteristics of amyloidosis patients according the presence $(n=18)$ or absence $(n=69)$ of RI (Table 2).The frequencies of the classical risk factors potentially associated with RI occurrence did not differ significantly between the patients with RI and those without RI: eleven of the patients with RI $(64.7 \%)$ had paroxysmal or permanent auricular fibrillation (vs. 
$35(51.5 \%)$ in the group without RI, $P=.33$ ), 11 had severe heart involvement (global strain below $10 \% ; 61.1 \%$ vs. $32(46.4 \%)$ in the group without RI, $P=.27)$, and three had nephrotic syndrome $(16.7 \%$ vs $4(5.9 \%)$ in the group without RI, $P=.14)$. Four of the 10 patients on anticoagulation treatment at the time of RI diagnosis were taking oral vitamin $\mathrm{K}$ antagonists (all these patients had international normalized ratios (INRs) in the therapeutic range) and six were taking oral direct anticoagulants. No other baseline findings other than proteinuria $(P=.03)$ differed between the groups of patients with and without RI. None of the patients underwent renal biopsy at the time of RI diagnosis, but RI was diagnosed in one of the five patients with renal biopsy-proven $\mathrm{AL}$ amyloidosis. This patient displayed massive, predominantly vascular amyloid deposits associated with partial arterial occlusion (Figure 4).

\section{Renal infarction is associated with kidney impairment in patients with cardiac amyloidosis}

Median baseline serum creatinine level and eGFR did not differ significantly between the groups of patients with and without RI ( $P=.61$ and $P=.72$, respectively) (Table 2). The median interval between amyloidosis diagnosis and renal scintigraphy did not differ between these two groups but RI was significantly associated with AKI at the time of renal scintigraphy (44.4 vs. $13.2 \%, P=.003$ ) (Table3). An analysis of AKI severity according to KDIGO criteria revealed that KDIGO stages 1 and 2 were more frequent among patients with RI than among those without RI $(P=.001$ and $P=.001$, respectively). After a similar mean follow-up in the two groups $(\mathrm{P}=.77)$, median serum creatinine level was found to have increased from baseline to last follow-up $(109 \mu \mathrm{mol} / \mathrm{L}$ (93-152) to $145 \mu \mathrm{mol} / \mathrm{L}$ (85-220) in the RI group, whereas it had not changed in the non-RI group (124 $\mu \mathrm{mol} / \mathrm{L}$ (94-152) to 125 $\mu \mathrm{mol} / \mathrm{L}(92-165))$. Analysis of the specific outcomes for the eight patients with AKI and RI at the time of renal scintigraphy revealed that two of these patients died during the month 
following RI diagnosis and two required renal replacement therapy (hemodialysis in two cases, followed by kidney transplantation in one case). Finally, the likelihood of RI on ${ }^{99 \mathrm{~m}} \mathrm{Tc}-$ DMSA scintigraphy was found to be higher in cardiac amyloidosis patients displaying AKI on the day of imaging than in patients without AKI (47.1\% vs. $14.5 \%, P=.003)$. We found that overall heart transplant-censored patient survival did not differ significantly between patients with and without a diagnosis of RI $(P=.64)$ (Figure 5). This finding remained non-significant for analyses according to the underlying amyloidosis disorder (patient survival with and without RI for the AL amyloidosis, ATTRwt and ATTRm subgroups) (data not shown). By contrast, we found that death-and heart transplant-censored renal survival was significantly lower in patients with RI $(P<.001)$ (Figure 6). 


\section{DISCUSSION}

In this study, the prevalence of RI, as demonstrated by ${ }^{99 \mathrm{~m}} \mathrm{Tc}-\mathrm{DMSA}$ renal scintigraphy, was relatively high (20.7\%) among the 87 patients with a definitive diagnosis of confirmed cardiac amyloidosis. CT scan is the gold standard method for RI confirmation, but this approach is unsuitable for use in patients at particular risk of developing iodinated contrast-induced nephropathy. ${ }^{17}$ In these patients, MRI should be considered as an alternative method, but this technique is contra indicated in patients with heart devices. As $60 \%$ and $61.6 \%$ of our cohort had heart devices and various stages of pre-existing CKD, respectively, we investigated the prevalence of RI in patients with cardiac amyloidosis by ${ }^{99 \mathrm{~m}} \mathrm{Tc}-\mathrm{DMSA}$ renal scintigraphy. Renal scintigraphy confirmed the presence of RI in 36 of 37 patients in the study performed by Hazanov et al and in all patients in the study performed by Lessman et al. ${ }^{10,18}$ Before starting to assess RI with ${ }^{99 \mathrm{~m}} \mathrm{Tc}-\mathrm{DMSA}$ renal scintigraphy, we validated this technique for this purpose by showing, in one kidney transplant recipient (without renal graft amyloidosis), a close correlation between renal biopsy, renal scintigraphy and MRI findings suggesting that ${ }^{99 m}$ Tc-DMSA renal scintigraphy is a potentially effective and useful tool for detecting RI in patients, in whom CT scans and MRI must be used with cautions.

Amyloid cardiomyopathy may be associated with thromboembolic events, mostly due to atrial fibrillation, leading to intracardiac thrombus formation. ${ }^{19}$ Some baseline characteristics, including those potentially associated with a higher likelihood of thromboembolic events differed between the AL amyloidosis, ATTRwt and ATTRm groups. Nevertheless, we found no difference in RI prevalence between patients with cardiac amyloidosis from the different groups defined on the basis of the underlying pathogenesis of amyloid production. In the meta-analysis carried out by Antopolsky et al., atrial fibrillation was identified as the main causal factor in $61 \%$ of published cases of RI. ${ }^{20}$ In a Korean survey, $55.7 \%$ of RI cases were 
of cardiac origin. ${ }^{21}$ In our study, a history of arrhythmic heart diseases was not significantly associated with a higher risk of RI. Thus, atrial amyloid infiltration may lead to the generation of atrial clots even in patients in sinus rhythm. ${ }^{22,23}$ Forty-nine patients were on anticoagulation therapy at the time of renal scintigraphy, with no difference in frequency between the RI and non-RI groups. Following the diagnosis of RI, the six patients taking oral direct anticoagulants were all switched onto heparin. These data suggest that oral anticoagulation treatment does not provide full protection against the risk of RI. Baseline echocardiographic features, including the number of patients with severe heart involvement and NT-proBNP levels, did not seem to differ between patients with and without RI. As these parameters were assessed at baseline, we cannot rule out the possibility of heart function declining at the time of or immediately before the occurrence of RI.

Thromboembolic events, whether arterial or venous, are major life-threatening complications of nephrotic syndrome. ${ }^{24}$ The higher proteinuria observed at baseline in the patients of the RI group may reflect more severe renal disease in these patients, but baseline eGFR and the number of patients with pre-existing CKD did not differ between the two groups. Unfortunately, in our study, proteinuria level was not assessed at the time of RI diagnosis but exclusively at baseline. Nevertheless, previous report suggests that RI may promote glomerular collapse associated with significant proteinuria. ${ }^{25}$ Mihout et al, described the case of a patient with major vascular AL amyloid deposits without significant glomerular involvement, suggesting that in situ renal vascular obstruction may promote RI. ${ }^{26}$ This hypothesis was previously put forward in a report on one patient with myocardial infarction. ${ }^{27}$ Predominantly vascular amyloid deposits remain a rare finding on renal biopsy specimens from patients with AL or ATTRm amyloidosis. ${ }^{28,29}$ By contrast, in the study of Said et al., in which 474 kidney biopsy specimens from amyloidosis patients (with no cases of ATTRm amyloidosis) were reviewed, the authors found that vascular involvement was frequent, but 
differed with the type of amyloidosis (more frequently observed in patients with AL or AA amyloidosis). Interestingly, in their study, Said et al. found no cases of cortical necrosis, but no MRI, CT scan or renal scintigraphy was performed before renal biopsy. ${ }^{30}$ Herrera et al. described the pathological spectrum of patients with plasma cell dyscrasia from a series of 77 autopsies (including 4 cases of amyloidosis). Only three patients were found to have renal infarcts and none of these patients had amyloidosis. ${ }^{31}$ Consistent with the possibility of arterial vascular events being related to vascular AL amyloids deposits in some tissues, we showed, in one patient extensive vascular AL amyloid deposits associated with partial arterial occlusion.

One of the most important results of this study is the finding that AKI in a context of cardiac amyloidosis may be due to RI. Several factors, including direct kidney damage due to amyloid deposits ${ }^{29,32}$, and indirect mechanisms of damage such as renal failure due to low cardiac output may be involved in the renal failure observed in these patients. ${ }^{5}$ In our study, $44.4 \%$ of patients with cardiac amyloidosis displayed AKI at the time of renal scintigraphy. Unfortunately, we could not date the occurrence of RI accurately. However, AKI seems to be a common finding during the course of RI. In the study by Oh et al. of 438 patients with RI, $20.1 \%$ of patients developed AKI. ${ }^{21}$ The risk of AKI in patients with RI is closely related to the presence or absence of a pre-existing CKD and to the severity of RI. Patients with cardiac amyloidosis frequently display pre-existing CKD; $22.2 \%$ of these patients in our cohort had bilateral RI, classified as grade II in $77.8 \%$. The finding that RI is more likely to occur in patients with cardiac amyloidosis that have AKI highlights the possibility that AKI may be due to RI. The potential value of initiating anticoagulant treatment to improve renal function requires further investigations, but such treatment should probably be discussed, to decrease the risk of new thromboembolic events. In a retrospective study, $32.5 \%$ of patients with RI diagnosis developed CKD within three months of discharge. ${ }^{33}$ The Kaplan-Meier curves for 
renal survival based on our results suggest that RI may be associated with a significant subsequent deterioration of renal function.

Our study has several limitations. First, we cannot draw any firm conclusions about the specific mechanisms involved in the occurrence of RI. The cause of RI in these patients remains unclear, but is probably multifactorial (due to hemostasis disorders for patients with significant proteinuria, extensive vascular renal amyloid deposits in some cases, and heart dysfunction and/or arrhythmic heart diseases promoting intracardiac thrombus formation and embolism). Second, although our study was not primarily designed to compare the prevalence of RI between patients with heart involvement due to amyloidosis and those with heart involvement of other aetiologies, we found that $25 \%$ of patients without a diagnosis of cardiac amyloidosis displayed RI. Unfortunately, the small number of patients without cardiac amyloidosis precluded any definitive conclusions about the RI prevalence, but our results nevertheless suggest that this condition is probably misdiagnosed in this population. Third, as mass spectrometry-based tissue typing was not performed, we cannot definitively exclude the possibility that the type of amyloidosis may have been mischaracterized in some patients. Fourth, the facilities were not available for renal scintigraphy every day of the week, so all patients with a diagnosis of cardiac amyloidosis referred in our institution were not included in this study. Nevertheless, we found that cardiac amyloidosis patients who did and did not undergo ${ }^{99 \mathrm{~m}}$ Tc-labeled DMSA renal scintigraphy had no different baseline eGFR values, suggesting a lack of selection bias according to baseline renal function. 


\section{CONCLUSION}

Our study suggests that RI should probably be added to the spectrum of renal manifestations related to systemic amyloidosis in cases of heart involvement. This study describes a relatively high frequency of RI in patients with amyloid and non-amyloid heart disease. It suggests that RI, which is generally considered a rare event, is more widespread in patients with heart failure than previously thought. Regardless of the type of amyloidosis, a diagnosis of RI should be considered in patients with unexplained AKI. Further studies are now required to evaluate the potential value and optimal type of curative anticoagulation therapy and to identify the mechanisms underlying RI in patients with cardiac amyloidosis. 


\section{ACKNOWLEDGMENTS:}

\section{REFERENCES}

1. Wechalekar AD, Gillmore JD, Hawkins PN: Systemic amyloidosis. Lancet. 2016; 387(10038): 2641-2654

2. Nuvolone M, Merlini G: Systemic amyloidosis: novel therapies and role of biomarkers. Nephrol Dial Transplant. 2017; 32(5):770-780

3. Larsen CP, Kossman RJ, Beggs ML, Solomon A, Walker PD: Clinical, morphologic, and genetic features of renal leukocyte chemotactic factor 2 amyloidosis. Kidney Int. 2014; 86(2): $378-382$

4. Gillmore JD, Damy $\mathrm{T}$, Fontana $\mathrm{M}$, et al.:A new staging system for cardiac transthyretin amyloidosis. Eur Heart J. 2018; 39(30):2799-2806

5. Falk RH:Diagnosis and management of the cardiac amyloidoses. Circulation. 2005; 112 (13): 2047-2060

6. Dember LM: Amyloidosis-associated kidney disease. J Am Soc Nephrol. 2006; 17(12): $3458-3471$

7. Khalighi MA, Dean Wallace W, Palma-Diaz MF: Amyloid nephropathy. Clin Kidney J. 2014; 7(2): 97-106

8. Lachmann HJ, Goodman HJ, Gilbertson JA, et al: Natural history and outcome in systemic AA amyloidosis. N Engl J Med. 2007;356(23): 2361-71

9. Palladini G, Hegenbart U, Milani P, et al.:A staging system for renal outcome and early markers of renal response to chemotherapy in $\mathrm{AL}$ amyloidosis. Blood. 2014;124(15):2325-2332

10. Hazanov N, Somin M, Attali M, et al: Acute renal embolism: Forty-four cases of renal infarction in patients with atrial fibrillation. Medicine (Baltimore). 2004;83(5): 292-299

11. Mahmoodi BK, ten Kate MK, Waanders F, et al :High absolute risks and predictors of venous and arterial thromboembolic events in patients with nephrotic syndrome: results from a large retrospective cohort study. Circulation. 2008;117(2): 224-230

12. Bourgault $\mathrm{M}$, Grimbert $\mathrm{P}$, Verret $\mathrm{C}$, et al: Acute renal infarction: A case series. Clin J Am Soc Nephrol. 2013;8(3): 392-398 
13. Hausfater P, Costedoat-Chalumeau N, Amoura Z, et al:AL cardiac amyloidosis and arterial thromboembolic events. Scand J Rheumatol. 2005;34(4): 315-319

14. Lang RM, Badano LP, Mor-Avi V, et al: Recommendations for cardiac chamber quantification by echocardiography in adults: An update from the American Society of Echocardiography and the European Association of Cardiovascular Imaging. J Am Soc Echocardiogr. 2015; 28(1): 1-39

15. Kidney Disease: Improving Global Outcomes (KDIGO) Acute Kidney injury Work Group. Clinical Practice Guideline for Acute Kidney injury. Kidney Int Suppl. 2012; 2(1): 1138

16. Kidney Disease: Improving Global Outcomes (KDIGO). Clinical Practice Guideline for the Evaluation and Management of Chronic Kidney Disease. Kidney Int Suppl. 2013; $3(1): 1-150$

17. Suzer O, Shirkhoda A, Jafri SZ,Madrazo BL, Bis KG, Mastromatteo JF: CT features of renal infarction. Eur J Radiol. 2002;44(1): 59-64

18. Lessman RK, Johnson SF, Coburn JW,Kaufman JJ : Renal artery embolism clinical features and long-term follow-up of 17 cases. Ann Intern Med. 1978;89(4): 477-82

19. Feng D, Edwards WD, Oh JK, et al:Intracardiac thrombosis and embolism in patients with cardiac amyloidosis. Circulation. 2007;116(21): 2420-2426

20. Antopolsky M, Simanovsky N, Stalnikowicz R, Salameh S, Hiller N: Renal infarction in the ED: 10-year experience and review of the literature. Am J Emerg Med. 2012;30(7): $1055-1060$

21. Oh YK, Yang CW, Kim YL, et al:Clinical characteristics and outcomes of renal infarction. Am J Kidney Dis. 2016;67(2): 243-250

22. Stables RH, Ormerod OJ: Atrial thrombi occurring during sinus rhythm in cardiac amyloidosis: evidence for atrial electromechanical dissociation. Heart. 1996; 75(4): 426

23. Dubrey S, Pollak A, Skinner M, Falk RH: Atrial thrombi occurring during sinus rhythm in cardiac amyloidosis: evidence for atrial electromechanical dissociation. Br Heart J. 1995;74(5): 541-544

24. Kerlin BA, Ayoob R, Smoyer WE: Epidemiology and pathophysiology of nephrotic syndrome-associated thromboembolic disease. Clin J Am Soc Nephrol. 2012;7(3): 513-520

25 Canaud G, Bruneval P, Noël LH, et al: Glomerular collapse associated with subtotal renal infarction in kidney transplant recipients with multiple renal arteries. Am J Kidney Dis. 2010;55(3):558-65

26. Mihout F, Joseph L, Brocheriou I, et al: Bilateral kidney infarction due to primary AL amyloidosis: A first case report. Medicine (Baltimore). 2015; 94(17): e777

27. Soma K, Takizawa M, Uozumi H, et al:A case of ST-elevated myocardial infarction resulting from obstructive intramural coronary amyloidosis. Int Heart J. 2010; 51(2): 134-136 
28. Eirin A, Irazabal MV, Gertz MA, et al: Clinical features of patients with immunoglobulin light chain amyloidosis (AL) with vascular-limited deposition in the kidney. Nephrol Dial Transpl. 2012; 27(3): 1097-101

29. Lobato L, Rocha A: Transthyretin amyloidosis and the kidney. Clin J Am Soc Nephrol. 2012;7(8): 1337-1346

30. Said SM, Sethi S, Valeri AM et al : Renal amyloidosis: origin and clinicopathologic correlations of 474 recent cases. Clin J Am Soc Nephrol. 2013; 8(9):1515-23

31. Herrera GA, Joseph L, Gu X, Hough A, Barlogie B: Renal pathologic spectrum in an autopsy series of patients with plasma cell dyscrasia. Arch Pathol Lab Med. 2004;128(8):8759.

32. Desport E, Bridoux F, Sirac C, et al; Centre national de référence pour l'amylose AL et les autres maladies par dépôts d'immunoglobulines monoclonales: Al amyloidosis. Orphanet J Rare Dis. 2012;7: 54

33. Lin WL, Seak CJ, Wu JY,Weng YM, Chen HC : Risk factors for development of chronic kidney disease following renal infarction: Retrospective evaluation of emergency room patients from a single center. PLoS One. 2014; 9(6):e98880 


\section{Figure legends}

\section{Figure 1. Flow-chart :}

This observational study was conducted in the Amyloidosis Referral Center of Henri-Mondor Hospital (France). Among 676 patients referred to our Amyloidosis center for suspected cardiac amyloidosis diagnosis a renal ${ }^{99} \mathrm{~m}$ Tc-DMSA scintigraphy was performed in 104 adult patients. Among them, amyloidosis with cardiac involvement was confirmed in 88 cases. Three groups of patients were identified according to the underlying amyloidosis disorder. In patients with cardiac amyloidosis, renal infarction was detected in 18 cases (20.7\%).

\section{Figure 2.Validation of the use of renal ${ }^{99 m}$ Tc-DMSA SPECT/CT for detecting biopsy- proven renal infarction in a grafted kidney}

A 56-year-old man with history of kidney transplantation for diabetic nephropathy, without amyloidosis, was referred to our nephrology department for suspected acute graft rejection. A renal biopsy was first performed. We then performed renal ${ }^{99 m}$ Tc-DMSA SPECT/CT and magnetic resonance imaging (MRI)

A: Kidney biopsy did not demonstrate acute cellular rejection, but two distinct areas were identified, including an extensive area of renal cortex necrosis (left) adjacent to preserved parenchyma (right) (hematoxylin-eosin-saffron x20).

B: Area of coagulation necrosis showing ghost outlines of tubules and glomeruli consistent with RI diagnosis (hematoxylin-eosin-saffron x100)

C: SPECT/CT fusion coronal view confirming the presence of 3 cortical defects (arrows). 
D: MRI confirming recent renal infarction, with triangular defective areas extending from the capsular surface into the medulla (arrows).

Figure 3 Illustration of ${ }^{99 m}$ Tc-DMSA-labeled scintigraphy in a patient with a diagnosis of cardiac amyloidosis and renal infarction

A: Anterior planar view showing 2 cortical defects (arrows).

B-C-D: SPECT/CT coronal views (B, SPECT; C, CT; D, fusion) confirming two grade-II cortical defects (plain arrows) and two additional grade-I defects (dashed arrows)

Figure 4 Kidney biopsy findings for a 59-year-old female patient with AL amyloidosis with cardiac and renal involvement and predominantly vascular amyloid deposits.

A: Expansion of the glomerular mesangium (arrow) and artery walls, with partial occlusion of the lumina (curved arrow) with amorphous acellular deposits (Masson's trichrome staining x200).

B: Congo Red staining confirmed the presence of predominantly vascular amyloid deposits (curved arrow) with slight mesangial involvement (arrow) (Congo Red staining x200).

Figure 5 Overall heart transplant-censored patient survival Figure 6 Overall death-and heart transplant-censored renal survival 


\section{Figure 1. Flow-chart.}

Patients referred to our Amyloidosis center for suspected cardiac amyloidosis diagnosis (1 October 2015 and 28 February 2018)

$$
\mathrm{n}=676
$$
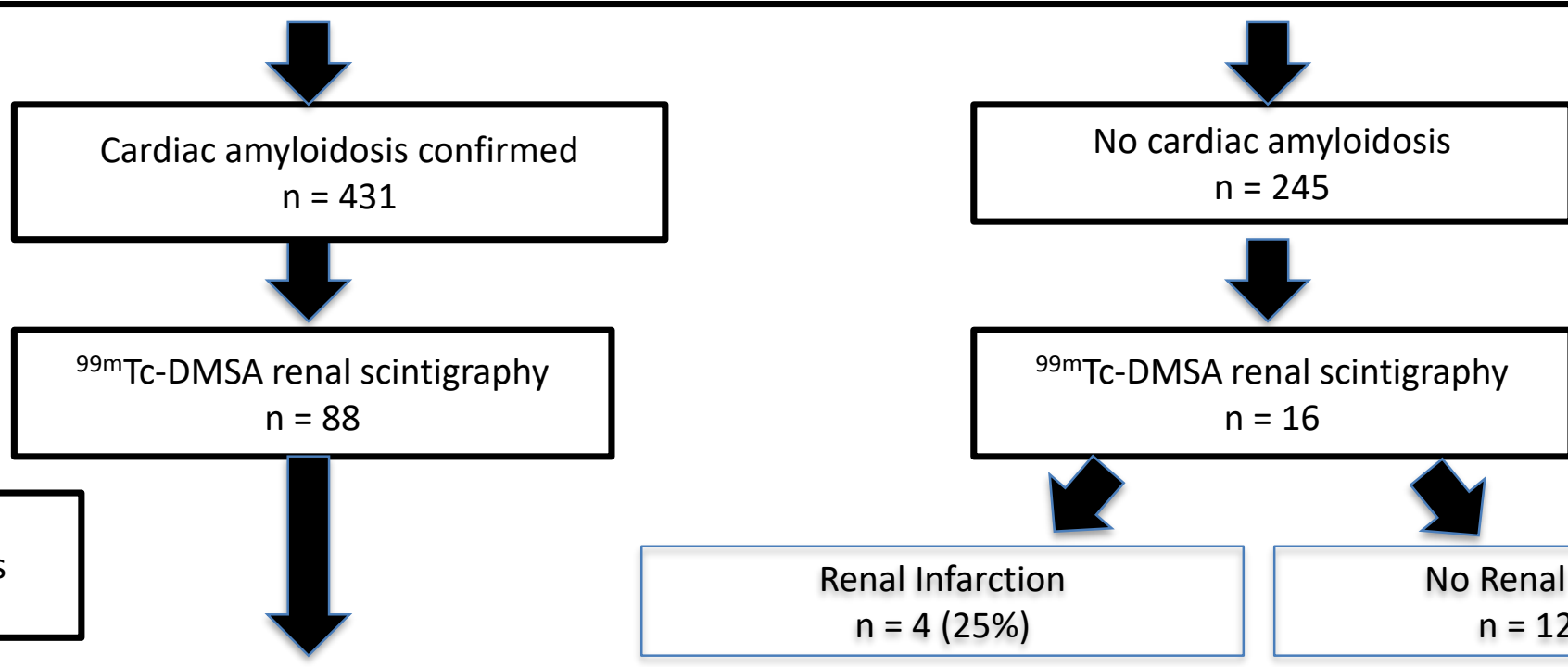

$$
\mathrm{n}=16
$$

Exclusion :

ApoA2 amyloidosis

$\mathrm{n}=1$

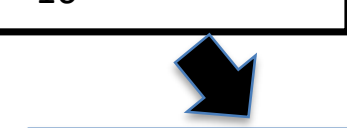

No Renal Infarction $\mathrm{n}=12(75 \%)$

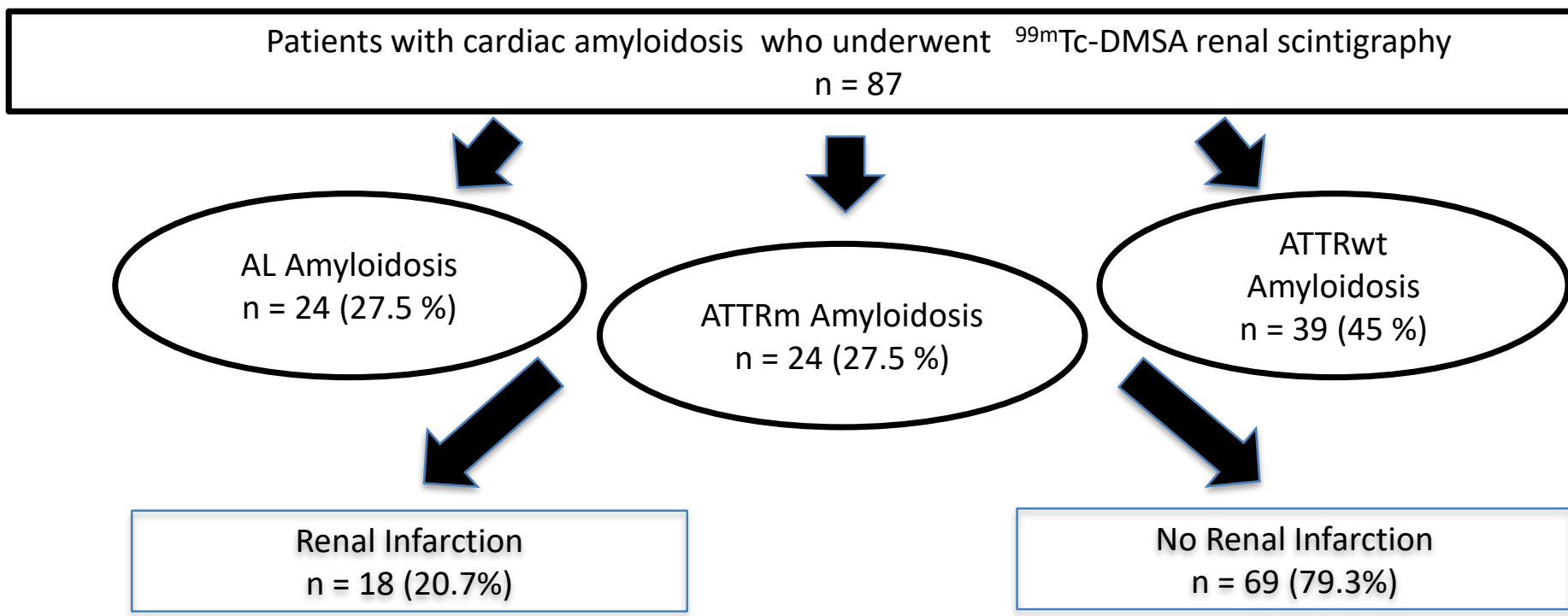

ATTRm = Mutated TTR amyloidosis. ATTRwt = Wild-type TTR amyloidosis. 
Figure 2. Validation of the use of renal ${ }^{99 m}$ TC-DMSA SPECT/CT for detecting biopsy-proven renal infarction in a grafted kidney

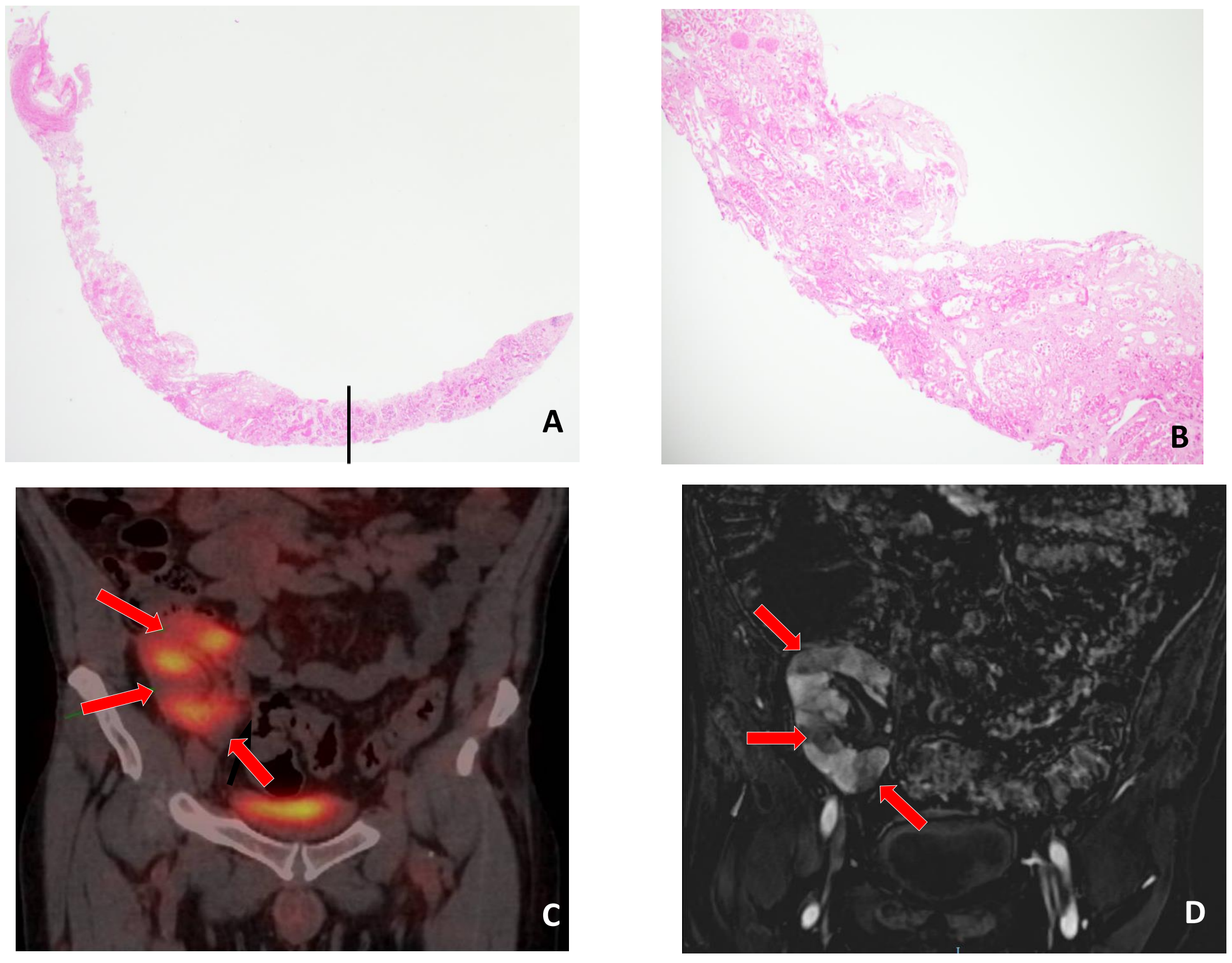


Figure 3 Illustration of ${ }^{99 m}$ Tc-DMSA-labeled scintigraphy in a patient with a diagnosis of cardiac amyloidosis and renal infarction
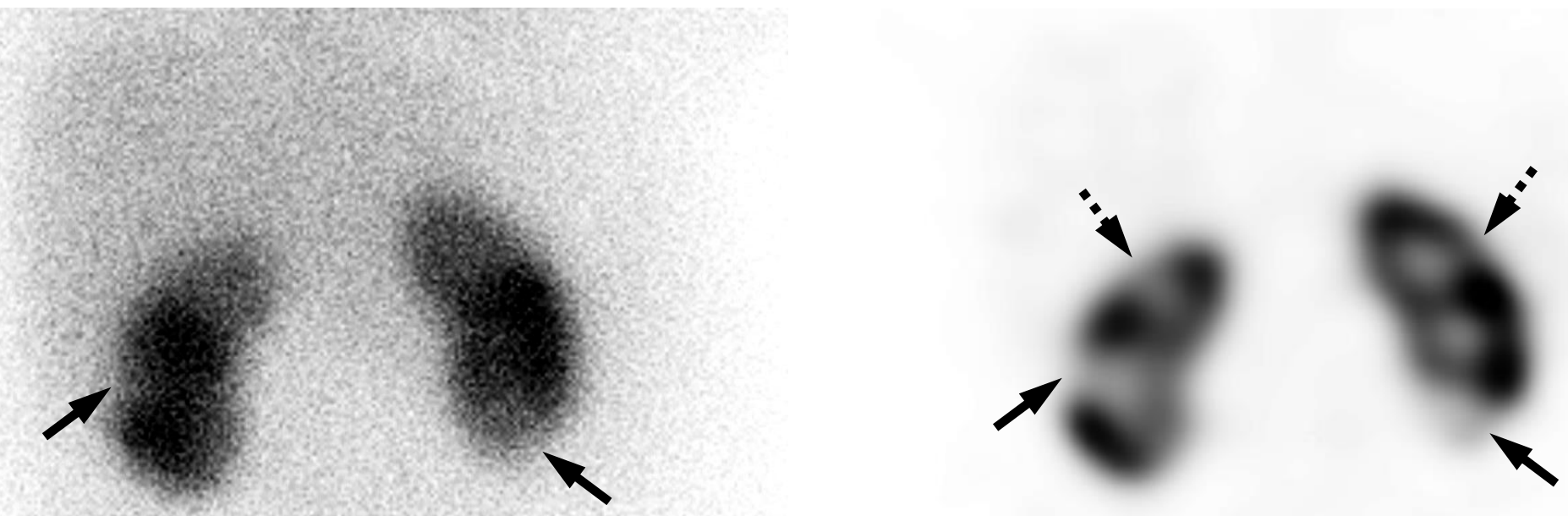

A

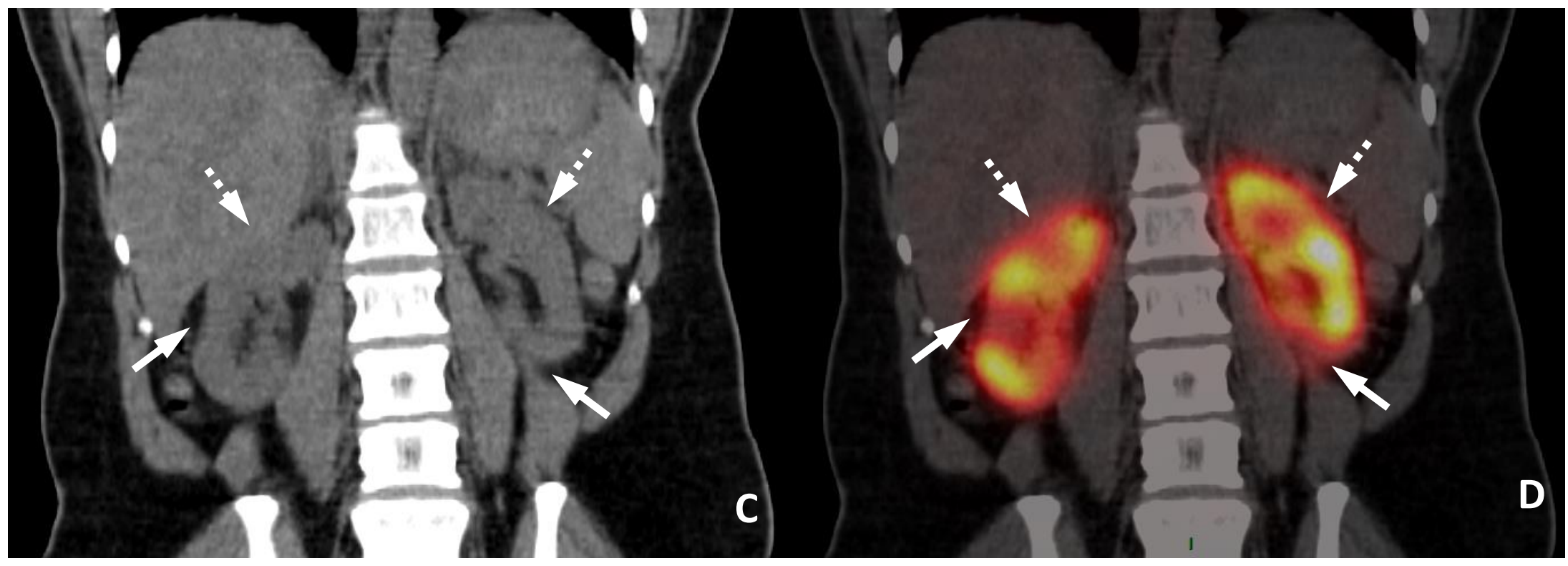


Figure 4 Kidney biopsy findings for a 59-year-old female patient with AL amyloidosis with cardiac and renal involvement and predominantly vascular amyloid deposits
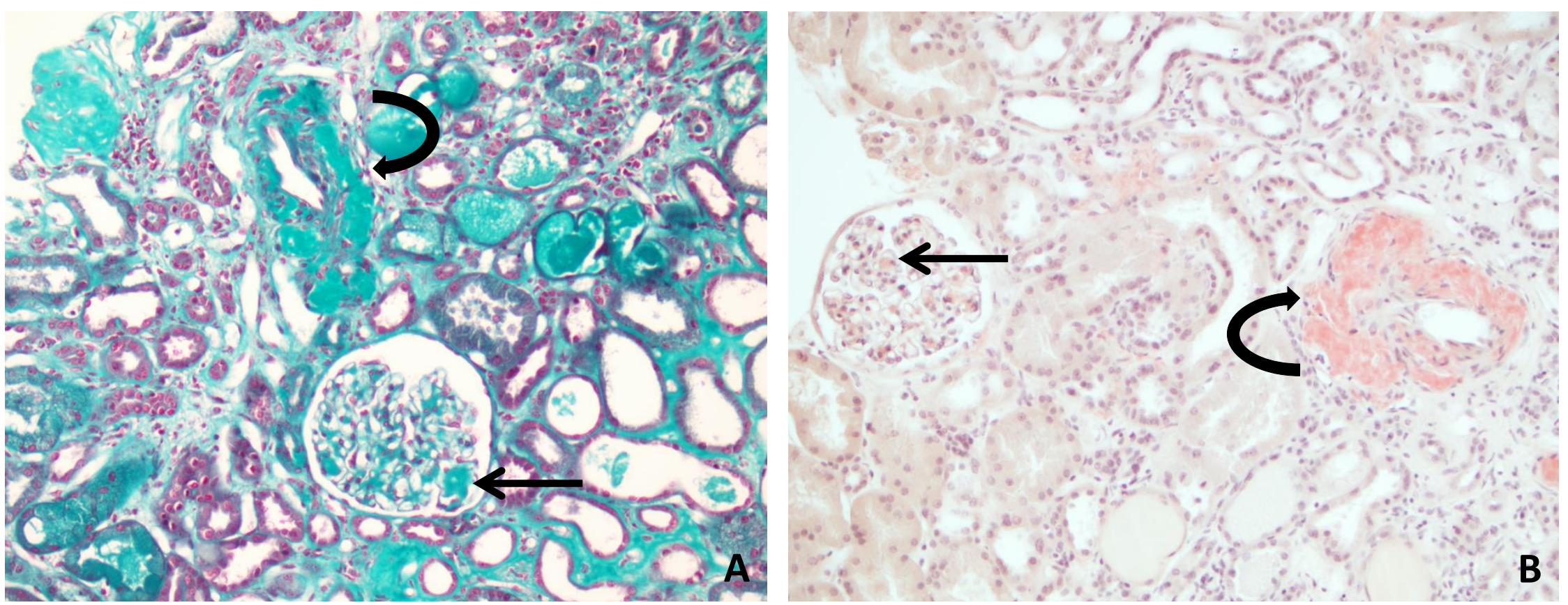
Figure 5. Overall heart transplant-censored patient survival

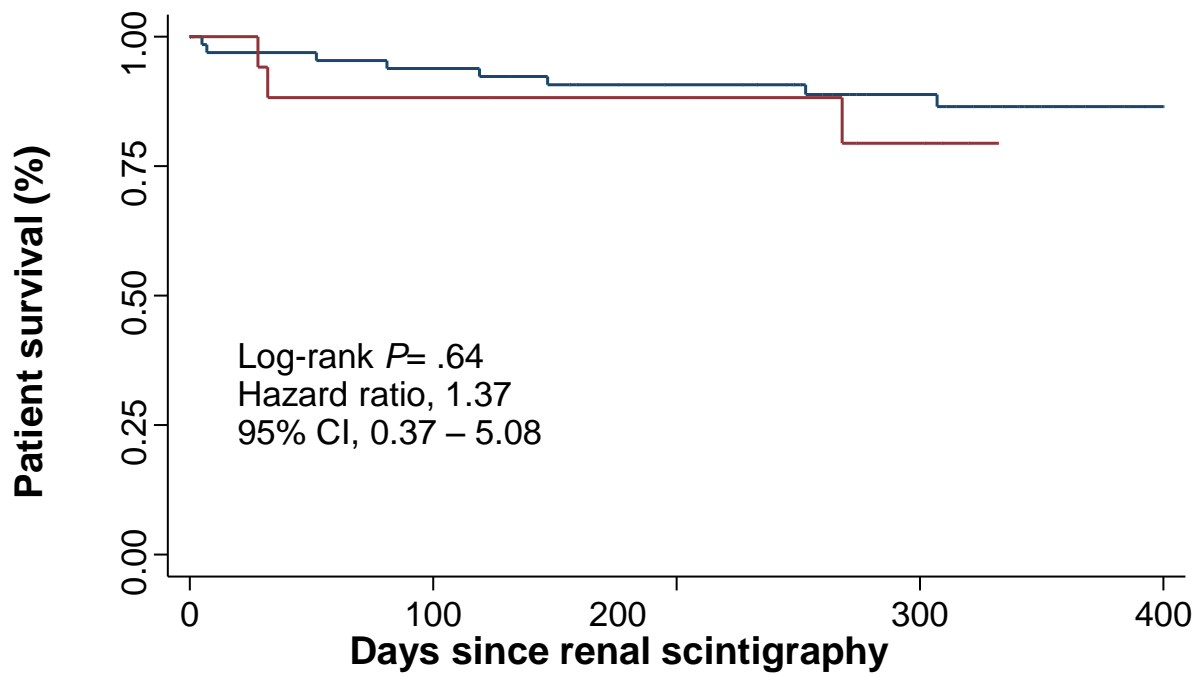

Number at risk

No renal infarction Renal infarction

69 18
61

15
53

13
39

8 


\section{Table 1: Baseline demographic, clinical, biological and echocardiographic characteristics, by underlying amyloidosis disorder}

\begin{tabular}{|c|c|c|c|c|c|}
\hline \multirow{2}{*}{$\begin{array}{l}\text { Variables } \\
\text { Amyloidosis type, } n(\%)(n=87)\end{array}$} & \multicolumn{4}{|c|}{$\begin{array}{c}\text { Amyloidosis } \\
(\mathbf{n}=\mathbf{8 7})\end{array}$} & \multirow[b]{2}{*}{$P$ value } \\
\hline & $\begin{array}{l}\text { Overall } \\
87(100)\end{array}$ & $\begin{array}{c}\text { AL } \\
24(27.5) \\
\end{array}$ & $\begin{array}{c}\text { ATTRm* } \\
24(27.5) \\
\end{array}$ & $\begin{array}{c}\text { ATTRwt } \\
39(45)\end{array}$ & \\
\hline \multicolumn{6}{|l|}{ Demographic and clinical characteristics } \\
\hline Age (years, $\left(25^{\text {th }}-75^{\text {th }}\right.$ percentiles $\left.)\right)(n=87)$ & $76(67-82)$ & $66(60-71)$ & $71(67-78)$ & $82(78-85)$ & $<.001$ \\
\hline Male, $n(\%)(n=87)$ & 66/87 (75.9) & $15 / 24(62.5)$ & $16 / 24(66.7)$ & $35 / 39(89.7)$ & .02 \\
\hline BMI $\left(25^{\text {th }}-75^{\text {th }}\right.$ percentiles $)(n=87)$ & $25(23-28)$ & $24(22-27)$ & $25(23-27)$ & $25(22-28)$ & .47 \\
\hline NYHA III-IV vs I-II class, $\mathrm{n}(\%)(n=80)$ & $37 / 80(46.2)$ & $13 / 22(59.1)$ & $7 / 21(33.3)$ & $17 / 37(45.9)$ & .24 \\
\hline \multicolumn{6}{|l|}{ Medical history } \\
\hline Paroxysmal or permanent AF, $n(\%)(n=85)$ & 46/85 (54.1) & $6 / 23(26.1)$ & $8 / 23(34.8)$ & $32 / 39(82.1)$ & $<.001$ \\
\hline Coronary artery disease, $n(\%)(n=83)$ & $5 / 83(6)$ & $1 / 23(4.3)$ & $2 / 23(8.7)$ & $2 / 37(5.4)$ & .81 \\
\hline Peripheral arterial disease of the lower limbs, $n(\%)(n=83)$ & $2 / 83(2.4)$ & $0 / 23(0)$ & $0 / 23(0)$ & $2 / 37(5.4)$ & .28 \\
\hline Acute cerebral ischemic stroke, $n(\%)(n=83)$ & $9 / 83(10.8)$ & $1 / 23(4.3)$ & $2 / 23(8.7)$ & $6 / 37(16.2)$ & .33 \\
\hline $\begin{array}{l}\text { Anticoagulation therapy ongoing on the day of renal scintigraphy, } \\
n(\%)(n=83)\end{array}$ & $49 / 83(59)$ & $4 / 23(17.4)$ & $11 / 23(47.8)$ & 34/37 (91.9) & $<.001$ \\
\hline \multicolumn{6}{|l|}{ Cardiovascular risk factors } \\
\hline Diabetes mellitus, $n(\%)(n=87)$ & $14 / 87(16.1)$ & $6 / 24(25)$ & $4 / 24(16.7)$ & $4 / 39(10.3)$ & .30 \\
\hline Dyslipidemia, $n(\%)(n=87)$ & $29 / 87(33.3)$ & $6 / 24(25)$ & $11 / 24(45.8)$ & $12 / 39(30.8)$ & .28 \\
\hline Smoking, $n(\%)(n=87)$ & 23/87 (26.4) & $6 / 24(25)$ & $6 / 24(25)$ & $11 / 39(28.2)$ & .95 \\
\hline Hypertension, $n(\%)(n=87)$ & $43 / 87(49.4)$ & $7 / 24(29.2)$ & $15 / 24(62.5)$ & $21 / 39(53.8)$ & .05 \\
\hline \multicolumn{6}{|l|}{ Echocardiographic parameters } \\
\hline $\operatorname{LVEF}\left(\%,\left(25^{\text {th }}-75^{\text {th }}\right.\right.$ percentiles $\left.)\right)(n=87)$ & $52(42-60)$ & $58(42-66)$ & $47(33-60)$ & $52(42-60)$ & .24 \\
\hline Global strain $\left(\%,\left(25^{\text {th }}-75^{\text {th }}\right.\right.$ percentiles $\left.)\right)(n=87)$ & $10(8-12)$ & $11(7-16)$ & $10(8-13)$ & $10(8-11)$ & .53 \\
\hline Global strain $<10 \%, n(\%)(n=87)$ & 43/87 (49.4) & $11 / 24(45.8)$ & $12 / 24(50)$ & $20 / 39(51.3)$ & .91 \\
\hline LVEDD $\left(\mathrm{mm},\left(25^{\mathrm{t}}-75^{\text {th }}\right.\right.$ percentiles $\left.)\right)(n=81)$ & $44.5(40-48)$ & $43(39-46)$ & $46(43-52)$ & $44(40-48)$ & .06 \\
\hline $\mathrm{Em} / \mathrm{Am} * *$ ratio $(n=32)$ & $1.85(0.9-3.01)$ & $1.55(0.88-2.55)$ & $3(0.9-3.95)$ & $1.9(0.75-2.05)$ & .41 \\
\hline Em/e' ratio $\left(25^{\text {th }}-75^{\text {th }}\right.$ percentiles $)(n=77)$ & $16.5(12-23)$ & $15(10.5-26.5)$ & $18(14-21)$ & $16(12.5-23)$ & .67 \\
\hline Left atrial enlargement, $n(\%)(n=87)$ & $43 / 87(49.4)$ & $13 / 24(54.2)$ & $8 / 24(33.3)$ & $22 / 39(56.4)$ & .18 \\
\hline \multicolumn{6}{|l|}{ Devices } \\
\hline PM or ICD, $n(\%)(n=85)$ & $51 / 85(60)$ & $12 / 23(52.2)$ & $13 / 23(56.5)$ & $26 / 39(66.7)$ & .49 \\
\hline \multicolumn{6}{|l|}{ Laboratory parameters } \\
\hline 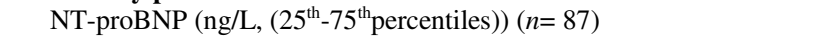 & $3253(1930-7544)$ & $6728(2423-9500)$ & $2289(1039-3803)$ & $3253(2153-7570)$ & .02 \\
\hline Troponin HS (ng/L, $\left(25^{\text {th }}-75^{\text {th }}\right.$ percentiles $\left.)\right)(n=87)$ & $72(51-104)$ & $74(53-102)$ & $72(55-110)$ & $68(48-102)$ & .70 \\
\hline Albumin level $\left(\mathrm{g} / \mathrm{L},\left(25^{\text {th }}-75^{\text {th }}\right.\right.$ percentiles $\left.)\right)(n=87)$ & $38(34-41)$ & $33(22-39)$ & $38(33-41)$ & $39(36-42)$ & .001 \\
\hline $\begin{array}{l}\text { Time between amyloidosis diagnosis and renal scintigraphy } \\
\left.\text { (days, }\left(25^{\text {th }}-7^{\text {th }} \text { percentiles }\right)\right)(n=87)\end{array}$ & $52(4-338)$ & $58(22-301)$ & $114(14-519)$ & $9(3-250)$ & .06 \\
\hline \multicolumn{6}{|l|}{ Biopsy pathological findings $(n=86)$} \\
\hline Accessory salivary gland biopsy, $n(\%)$ & 73/86 (84.9) & $16 / 23(69.6)$ & 21/24 (87.5) & $36 / 39(92.3)$ & .05 \\
\hline Positive accessory salivary gland biopsy, $n(\%)$ & $32 / 73(43.8)$ & $10 / 16(62.5)$ & $12 / 21(57.1)$ & $10 / 36(27.8)$ & \\
\hline Endomyocardial biopsy, $n(\%)$ & 28/86 (32.6) & $11 / 23(47.8)$ & $10 / 24(41.7)$ & 7/39 (17.9) & .03 \\
\hline Positive endomyocardial biopsy, $n(\%)$ & $27 / 28(96.4)$ & $11 / 11(100)$ & $9 / 10(90)$ & $7 / 7(100)$ & \\
\hline Kidney biopsy, $n(\%)$ & $5 / 86(5.8)$ & $5 / 23(21.7)$ & $0 / 24(0)$ & $0 / 39(0)$ & .001 \\
\hline Positive kidney biopsy, $n(\%)$ & $5 / 5(100)$ & $5 / 5(100)$ & $0 / 0(0)$ & $0 / 0(0)$ & \\
\hline \multicolumn{6}{|l|}{ AL amyloidosis characteristics $(n=24)$} \\
\hline Monoclonal Kappa light chain, $n(\%)(n=24)$ & & $4 / 24(16.7)$ & & & \\
\hline Monoclonal Lambda light chain, $n(\%)(n=24)$ & & $20 / 24(83.3)$ & & & \\
\hline $\begin{array}{l}\text { Initial serum free light chain concentration }(\mathrm{mg} / \mathrm{L}) \text {, } \\
\left.\left(25^{\text {th }}-75^{\text {th }} \text { percentiles }\right)\right)(n=23)\end{array}$ & & $262(175-339)$ & & & \\
\hline On chemotherapy before renal scintigraphy, $n(\%)(n=23)$ & & $15 / 23(65.2)$ & & & \\
\hline On Velcade before renal scintigraphy, $n(\%)(n=23)$ & & $15 / 23(65.2)$ & & & \\
\hline On alkylating agent before renal scintigraphy, $n(\%)(n=23)$ & & $14 / 23(60.9)$ & & & \\
\hline On thalidomide before renal scintigraphy, $n(\%)(n=23)$ & & $1 / 23(4.3)$ & & & \\
\hline \multicolumn{6}{|l|}{ Renal characteristics } \\
\hline Urinary protein/creatinine $\left(\mathrm{mg} / \mathrm{mmol},\left(25^{\text {th }}-75^{\text {th }}\right.\right.$ percentiles $\left.)\right)(n=61)$ & $16(9-49)$ & $50(22-233)$ & $14(10-43)$ & $9(4-19)$ & $<.001$ \\
\hline Nephrotic syndrome, $n(\%)(n=86)$ & 7/86 (8.1) & 7/23(30.4) & $0 / 24(0)$ & $0 / 39(0)$ & $<.001$ \\
\hline Serum creatinine level $\left(\mu \mathrm{mol} / \mathrm{L},\left(25^{\text {th }}-75^{\text {th }}\right.\right.$ percentiles $\left.)\right)(n=86)$ & $122(94-152)$ & $116(89-167)$ & $126(89-153)$ & $122(96-151)$ & .81 \\
\hline eGFR(MDRD, $\left.\mathrm{mL} / \mathrm{mn} / 1.73 \mathrm{~m}^{2}\right),\left(25^{\text {th }}-75^{\text {th }}\right.$ percentiles $)(n=86)$ & $55(41-72)$ & $58(34-74)$ & $53(40-76)$ & $53(42-69)$ & .82 \\
\hline Pre-existing CKD, $n(\%)(n=86)$ & $53 / 86(61.6)$ & $15 / 24(62.5)$ & $15 / 24(62.5)$ & $23 / 38(60.5)$ & .98 \\
\hline Stage $3 \mathrm{~A}, n(\%)$ & $22 / 86(25.6)$ & $7 / 24(29.2)$ & $8 / 24(33.3)$ & $7 / 38(18.4)$ & .07 \\
\hline
\end{tabular}


Qualitative data are expressed asn (\%), quantitative data are expressed as means $( \pm \mathrm{SD})$ or medians (IQR) as appropriate

* TTR genetic variants found in patients with ATTRm included Val122Ile $(n=15)$, Val122Ala $(n=1)$, Val30Met $(n=1)$, Ser77Tyr $(n=2)$, Ile107Val $(n=1)$, Ile68Leu $(n=1)$, Thr49Ile $(n=1)$, Gly47Ala $(n=1)$, and Arg21Gln $(n=1)$. Four of 24 ATTRm patients were on tafamidis treatment before renal scintigraphy.

** In patients in sinus rhythm, by definition

ATTRm $=$ mutated TTR amyloidosis, ATTRwt $=$ wild-type TTR amyloidosis

BMI =body mass index

NYHA = New York Heart Association dyspnea class

$\mathrm{AF}=$ atrial fibrillation

Global strain= left ventricular global longitudinal strain

$\mathrm{LVEDD}=$ left ventricular end-diastolic diameter, $\mathrm{LVEF}=$ left ventricular ejection fraction $\mathrm{Em} / \mathrm{Am}=$ ratio of early (Em wave) to late (Am wave) filling of the left ventricle (transmitral diastolic peak flow velocities)

Em/e' = ratio of early (Em wave) filling of the left ventricle (transmitral diastolic peak flow velocity) to early diastolic mitral annular velocity (e' wave)

$\mathrm{NT}$-proBNP $=\mathrm{N}$-terminal prohormone of brain natriuretic peptide

$\mathrm{PM}=$ pacemaker, $\mathrm{ICD}=$ implantable cardioverter defibrillator

eGFR $=$ estimated glomerular filtration rate, $\mathrm{MDRD}=$ modification of diet in renal disease formula , $\mathrm{CKD}=$ chronic kidney disease 


\section{Table 2: Baseline demographic, clinical, biological and echocardiographic characteristics in patients with cardiac amyloidosis with and without renal infarction}

\begin{tabular}{|c|c|c|c|}
\hline \multirow[t]{2}{*}{ Variables } & \multicolumn{2}{|c|}{ Renal infarction } & \multirow[b]{2}{*}{$P$ value } \\
\hline & $\begin{array}{c}\text { Yes } \\
(n=18)\end{array}$ & $\begin{array}{c}\text { No } \\
(n=69)\end{array}$ & \\
\hline \multicolumn{4}{|l|}{ Demographic and clinical characteristics } \\
\hline Age (years, $\left(25^{\text {th }}-75^{\text {th }}\right.$ percentiles $\left.)\right)(n=87)$ & $72(64-80)$ & $77(68-82)$ & .32 \\
\hline Male, $n(\%)(n=87)$ & $12 / 18(66.7)$ & $54 / 69(78.3)$ & .31 \\
\hline BMI $\left(25^{\text {th }}-75^{\text {th }}\right.$ percentiles $)(n=87)$ & $25(22-27)$ & $25(23-28)$ & .48 \\
\hline NYHA III-IV vs.I-II, $n(\%)(n=80)$ & $8 / 18(44.4)$ & 29/62 (46.8) & .86 \\
\hline \multicolumn{4}{|l|}{ Medical history } \\
\hline Paroxysmal or permanent AF, $n(\%)(n=85)$ & $11 / 17$ (64.7) & $35 / 68(51.5)$ & .33 \\
\hline Coronary artery disease, $n(\%)(n=83)$ & $0 / 17(0)$ & $5 / 66(7.6)$ & .24 \\
\hline Peripheral arterial disease of the lower limbs, $n(\%)(n=83)$ & $1 / 17(5.9)$ & $1 / 66(1.5)$ & .30 \\
\hline Acute cerebral ischemic stroke, $n(\%)(n=83)$ & $1 / 17(5.9)$ & $8 / 66(12.1)$ & .46 \\
\hline Anticoagulation therapy ongoing on the day of renal scintigraphy, $n(\%)(n=83)$ & $10 / 17(58.8)$ & $39 / 66(59.1)$ & $>.99$ \\
\hline \multicolumn{4}{|l|}{ Cardiovascular risk factors } \\
\hline Diabetes mellitus, $n(\%)(n=87)$ & $2 / 18(11.1)$ & 12/69 (17.4) & .52 \\
\hline Dyslipidemia, $n(\%)(n=87)$ & $8 / 18(44.4)$ & 21/69 (30.4) & .26 \\
\hline Smoking, $n(\%)(n=87)$ & $4 / 18(22.2)$ & $19 / 69(27.5)$ & .65 \\
\hline Hypertension, $n(\%)(n=87)$ & $11 / 18(61.1)$ & $32 / 69(46.4)$ & .27 \\
\hline \multicolumn{4}{|l|}{ Echocardiographic parameters } \\
\hline $\operatorname{LVEF}\left(\%,\left(25^{\text {th }}-75^{\text {th }}\right.\right.$ percentiles $\left.)\right)(n=87)$ & $52(40-63)$ & $52(41-60)$ & .88 \\
\hline Global strain $\left(\%,\left(25^{\text {th }}-75^{\text {th }}\right.\right.$ percentiles $\left.)\right)(n=87)$ & $9(7-11)$ & $11(8-13)$ & .34 \\
\hline Global strain <10\%, $n(\%)(n=87)$ & $11 / 18(61.1)$ & $32 / 69$ (46.4) & .27 \\
\hline LVEDD (mm, $\left(25^{\text {th }}-75^{\text {th }}\right.$ percentiles $\left.)\right)(n=81)$ & $45(43.5-52.5)$ & $44(40-48)$ & .05 \\
\hline $\mathrm{Em} / \mathrm{Am} *$ ratio $(n=32)$ & $1.55(0.78-2.95)$ & $1.9(0.9-3.18)$ & .85 \\
\hline Em/e' ratio $\left(25^{\text {th }}-75^{\text {th }}\right.$ percentiles $)(n=77)$ & $16(9-20)$ & $17(13-23)$ & .64 \\
\hline Left atrial enlargement, $n(\%)(n=87)$ & $6 / 18(33.3)$ & $37 / 69(53.6)$ & .19 \\
\hline \multicolumn{4}{|l|}{ Devices } \\
\hline PM or ICD, $n(\%)(n=85)$ & $8 / 17(47.1)$ & $43 / 68(63.2)$ & .22 \\
\hline \multicolumn{4}{|l|}{ Biological parameters } \\
\hline NT-proBNP (ng/L, $\left(25^{\text {th }}-75^{\text {th }}\right.$ percentiles $\left.)\right)(n=87)$ & $3364(2227-9740)$ & $3523(1642-7011)$ & .38 \\
\hline Troponin HS (ng/L, $\left(25^{\text {th }}-75^{\text {th }}\right.$ percentiles $\left.)\right)(n=87)$ & $73(58-104)$ & $72(47-104)$ & .54 \\
\hline Albumin level $\left(\mathrm{g} / \mathrm{L},\left(25^{\text {th }}-75^{\text {th }}\right.\right.$ percentiles $\left.)\right)(n=87)$ & $37(30-41)$ & $38(34-41)$ & .41 \\
\hline Amyloidosis type $(n=87)$ & & & .80 \\
\hline $\mathrm{AL}, n(\%)$ & $6 / 18(33.3)$ & $18 / 69(26.1)$ & \\
\hline ATTRm, $n(\%)$ & $5 / 18(27.8)$ & $19 / 69(27.5)$ & \\
\hline ATTRwt, $n(\%)$ & $7 / 18(38.9)$ & $32 / 69(46.4)$ & \\
\hline $\begin{array}{l}\text { Timebetween amyloidosis diagnosis and renal scintigraphy } \\
\left(\text { days, }\left(25^{\text {th}}-\mathbf{7 5}^{\text {th }} \text { percentiles }\right)\right)(n=87)\end{array}$ & $51(7-354)$ & $52(4-375)$ & .71 \\
\hline \multicolumn{4}{|l|}{ AL amyloidosis characteristics $(n=24)$} \\
\hline Monoclonal Kappalight chain $(n=24)$ & $1 / 6(16.7)$ & $3 / 18(16.7)$ & $>.99$ \\
\hline Monoclonal Lambda light chain $(n=24)$ & $5 / 6(83.3)$ & $15 / 18(83.3)$ & $>.99$ \\
\hline Initial serum free light chain concentration $\left(\mathrm{mg} / \mathrm{dL},\left(25^{\text {th }}-75^{\text {th }}\right)\right)(\mathrm{n}=23)$ & $258(184-319)$ & $262(169-387)$ & .89 \\
\hline On chemotherapy before renal scintigraphy, $n(\%)(n=23)$ & $5 / 6(83.3)$ & $10 / 17(58.8)$ & .28 \\
\hline On Velcade before renal scintigraphy, $n(\%)(n=23)$ & $5 / 6(83.3)$ & 10/17 (58.8) & .28 \\
\hline On alkylating agent before renal scintigraphy, $n(\%)(n=23)$ & $5 / 6(83.3)$ & $9 / 17(52.9)$ & .19 \\
\hline On thalidomide before renal scintigraphy, $n(\%)(n=23)$ & $0 / 6(0)$ & $1 / 17(5.9)$ & .54 \\
\hline \multicolumn{4}{|l|}{ ATTRm characteristics } \\
\hline Tafamidis before renal scintigraphy, $n(\%)(n=23)$ & $0 / 5(0)$ & $4 / 18(22.2)$ & .24 \\
\hline \multicolumn{4}{|l|}{ Renal characteristics } \\
\hline Urinary protein/creatinine ratio $\left(\mathrm{mg} / \mathrm{mmol},\left(25^{\text {th }}-75^{\text {th }}\right.\right.$ percentiles $\left.)\right)(n=61)$ & $55(13-200)$ & $11(8-35)$ & .03 \\
\hline Nephrotic syndrome, $n(\%)(n=86)$ & $3 / 18(16.7)$ & $4 / 68(5.9)$ & .14 \\
\hline Serum creatinine concentration, $\left(\mu \mathrm{mol} / \mathrm{L},\left(25^{\text {th }}-75^{\text {th }}\right.\right.$ percentiles $\left.)\right)(n=86)$ & $109(93-152)$ & $124(94-152)$ & .61 \\
\hline 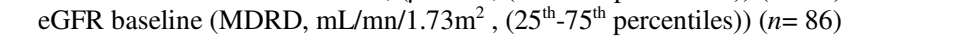 & $57(39-73)$ & $55(41-71)$ & .72 \\
\hline Pre-existing CKD, $n(\%)(n=86)$ & $9 / 18(50)$ & 44/68 (64.7) & .25 \\
\hline Stage $3 \mathrm{~A}, n(\%)$ & $3 / 18(16.7)$ & 19/68 (27.9) & .31 \\
\hline \multirow[t]{2}{*}{ Stage $3 \mathrm{~B}, n(\%)$} & $6 / 18(33.3)$ & $18 / 68(26.5)$ & \\
\hline & & & .31 \\
\hline
\end{tabular}




\begin{tabular}{|lrr|}
\hline Stage $4, n(\%)$ & $0 / 18(0)$ & .31 \\
Stage $5, n(\%)$ & $0 / 18(0)$ & $7 / 68(10.3)$ \\
\hline
\end{tabular}

Qualitative data are expressed as $n(\%)$, quantitative data are expressed as means $( \pm \mathrm{SD})$ or medians (IDR), as appropriate

* In patients in sinus rhythm, by definition

ATTRm $=$ mutated TTR amyloidosis, ATTRwt $=$ wild-type TTR amyloidosis

BMI =body mass index

NYHA = New York Heart Association dyspnea class

$\mathrm{AF}=$ atrial fibrillation

Global strain= left ventricular global longitudinal strain

$L V E D D=$ left ventricular end-diastolic diameter, $L V E F=$ left ventricular ejection fraction $\mathrm{Em} / \mathrm{Am}=$ ratio of early ( $\mathrm{E}$ wave) to late (A wave) filling of the left ventricle (transmitral diastolic peak flow velocities)

$\mathrm{Em} / \mathrm{e}^{\prime}=$ ratio of early (E wave) filling of the left ventricle (transmitral diastolic peak flow velocity) to early diastolic mitral annular velocity (e' wave)

$\mathrm{NT}$-proBNP=N-terminal prohormone of brain natriuretic peptide

$\mathrm{PM}=$ pacemaker, $\mathrm{ICD}=$ implantable cardioverter defibrillator

$\mathrm{eGFR}=$ estimated glomerular filtration rate, MDRD $=$ modification of diet in renal disease formula , $\mathrm{CKD}=$ chronic kidney disease 
Table 3: Clinical and biological data on the day ${ }^{99 m}$ Tc-labeled DMSA scintigraphy, in patients with cardiac amyloidosis with and without renal infarction

\begin{tabular}{|c|c|c|c|}
\hline \multirow[t]{2}{*}{ Variable } & \multicolumn{2}{|c|}{ Renal infarction } & \multirow[b]{2}{*}{$P$ value } \\
\hline & $\begin{array}{c}\text { Yes } \\
(n=18)\end{array}$ & $\begin{array}{c}\text { No } \\
(n=69)\end{array}$ & \\
\hline \multicolumn{4}{|l|}{ Clinical findings } \\
\hline $\mathrm{SBP}\left(\mathrm{mmHg},\left(25^{\text {th }}-75^{\text {th }}\right.\right.$ percentiles $\left.)\right)(n=81)$ & $118(108-131)$ & $125(112-138)$ & .39 \\
\hline $\mathrm{DBP}\left(\mathrm{mmHg},\left(25^{\text {th }}-75^{\text {th }}\right.\right.$ percentiles $\left.)\right)(n=81)$ & $72(66-75)$ & $70(65-79)$ & .94 \\
\hline HR (beats/min, $\left(25^{\text {th }}-75^{\text {th }}\right.$ percentiles $\left.)\right)(n=81)$ & $78(70-89)$ & $75(67-86)$ & .30 \\
\hline Abdominal pain, $n(\%)(n=77)$ & $0 / 16(0)$ & $1 / 61(1.6)$ & .61 \\
\hline Fever, $n(\%)(n=77)$ & $0 / 16(0)$ & $0 / 61(0)$ & $>.99$ \\
\hline \multicolumn{4}{|l|}{ Biological data } \\
\hline LDH (IU/L, $\left(25^{\text {th }}-75^{\text {th }}\right.$ percentiles $\left.)\right)(n=45)$ & $263(243-361)$ & $276(239-312)$ & .38 \\
\hline Neutrophil count $\left(/ \mathrm{mm}^{3},\left(25^{\text {th }}-75^{\text {th }}\right.\right.$ percentiles $\left.)\right)(n=81)$ & $4000(2250-5700)$ & $4200(3225-5175)$ & .47 \\
\hline C-reactive protein concentration $\left(\mathrm{mg} / \mathrm{L},\left(25^{\text {th }}-75^{\text {th }}\right.\right.$ percentiles $\left.)\right)(n=84)$ & $2.5(1.5-5.7)$ & $2.6(1-6.8)$ & .35 \\
\hline \multicolumn{4}{|l|}{ Renal function parameters } \\
\hline Serum creatinine concentration $\left(\mu \mathrm{mol} / \mathrm{L},\left(25^{\text {th }}-75^{\text {th }}\right.\right.$ percentiles $\left.)\right)(n=87)$ & $149(88-205)$ & $127(92-165)$ & .38 \\
\hline AKI on the day of renal scintigraphy, $n(\%)(n=86)$ & $8 / 18(44.4)$ & $9 / 68(13.2)$ & .003 \\
\hline KDIGO $1, n(\%)$ & $5 / 18(27.8)$ & $9 / 68(13.2)$ & .001 \\
\hline KDIGO $2, n(\%)$ & $3 / 18(16.7)$ & $0 / 68(0)$ & .001 \\
\hline KDIGO $3, n(\%)$ & $0 / 18(0)$ & $0 / 68(0)$ & $>.99$ \\
\hline
\end{tabular}

Qualitative data are expressed as $n(\%)$, quantitative data are expressed as means $( \pm \mathrm{SD})$ or medians (IDR), as appropriate

$\mathrm{SBP}=$ systolic blood pressure, $\mathrm{DBP}=$ diastolic blood pressure, $\mathrm{HR}=$ heart rate, $\mathrm{LDH}=$ lactate dehydrogenase

$\mathrm{AKI}=$ acute kidney injury, $\mathrm{CKD}=$ chronic kidney disease

KDIGO= Kidney Disease Improving Global Outcomes 